\title{
NOVEL PROPOSAL FOR AN ON LINE AND IN REAL TIME AIR QUALITY MONITORING GADGET
}

\author{
Drd. Ing. Matei Laurentiu Lordos ${ }^{1 *}$, \\ ${ }^{1}$ Universitatea Politehnica Timisoara, Piata Victoriei 2, 30006,.Timisoara, \\ Romania \\ * mateilordos@gmail.com
}

\begin{abstract}
Air quality is a very important issue for the contemporary society, in order to sustain its future. Due to the fact that in Timişoara city, as in most metropolitan areas with urban agglomerations and developed transport system, atmospheric pollution rules and maximum admitted values are frequently exceeded, an air quality monitoring system, more simple and not costly, is needed, to complete the real time pollution level/picture, in areas that are not constantly monitored by national grid systems. Its usefulness is to prevent possible major air pollution, which can put people's life, sustainable development and wellbeing at risk. The present paper refers to a proposal is to design and develop a mobile air quality measurement device. Measurements will be accomplished in real time. There are two ways to realize this device: (i) first, to operate autonomously, with a led display, on which real-time measurements are taken; (ii) And the second variant is that the device works with a mobile device and communicates through a data protocol. The transducer will measure the concentration of PM2.5, PM10, $\mathrm{NO}_{\mathrm{x}}$. Throughout this paper highlights the advantages and disadvantages of each of the two solutions (gadgets) proposed above.
\end{abstract}

\section{Introduction}

From the beginning of his existence on the planet, the human beings, through its activities had negative influences on the environmental factors -air, water, soil-elements without which, life and standards cannot be conceived. There is a critical point that influences, irreversible on most cases, especially the pollution level of the environmental factors. Even nature's defense capacity intervenes, one has to develop as well strict regulations (international, national) hoping for rebalancing, or at least reduction of the present level, versus a basis, that is selected according to the effects registered.

Presently, it seems that the pollution of the environment through the uncontrolled activity of man is reaching a critical point, surpassing the defense limits of nature. As result climate changes, irreversible and inflexible fauna and flora mutations occur, life style must be changed, access to food and water resources, that are most and most more reduced for poor countries, must be covered and solved.

Pollution is a phenomenon that does not take into account the physical boundaries of states, the level of development or the wishes\& nest intentions of the population. This means that the responsibilities and the means of prevention are attributed to all states.

The economical industrial development of Romania, in the past decades, has raised important problems regarding the fight against pollution of the atmosphere. The interest was in finding the most effective ways to captivate and purge residual gases before their evacuation in the surrounding environment as well as in perfecting the technological equipment and the fabrication technology by using primary sources that are less traumatizing for man. It is expected that through these methods, the creation of optimal work conditions, which can prevent work accidents and professional illness as well as diminishing the emission of harmful substances into the environment, can be achieved [1]. In the National Network of Air Quality Automatic Monitoring the following pollutants are measured: $\mathrm{SO} 2, \mathrm{NO}, \mathrm{NO}_{2}, \mathrm{NO}_{\mathrm{x}}$, suspended dusts - PM10 and PM2.5, CO, $\mathrm{O}_{3}$, benzene and lead. Currently, in Romania the 
National Network of Air Quality Monitoring (RNMCA) comprises permanent air quality monitoring stations, and 17 mobile labs, endowed with automatic equipments to measure the concentrations of major air pollutants. RNMCA includes 41 local centers, which gather and disseminate to public information panels data from stations and transmit them after primary validation for certification of the Bucharest National Reference Laboratory (LNR) [2].

According to the simulation made with program ISC3 View is observed that the level of $\mathrm{NO}_{\mathrm{X}}$ in Timisoara is not strongly affected by emissions from the power plant CET South (Thermoelectrically power point Timisoara South. One concluded that the main polluting factor in urban areas is road traffic. It is noticed that the concentration of $\mathrm{NO}_{\mathrm{X}}$ during the day at peak hours is 6 times higher than the values measured at night [3].

\section{Air pollution is a major problem}

\section{In general}

From the beginning, it needs to be specified that the atmospheric air is one of the environmental factors that is hard to control because the pollutants, once they get into the atmosphere, are quickly dispersed and can no longer be captured and purged on ground. The pollutants in the air may be substances foreign to the background composition of the air or to the substances, which are found in this composition and which, according to their concentration and time of action, exercise a harmful effect on man and environment.

Air pollution is a serious global public health problem that is managed most effectively by collective (societal) action to control emissions of both primary air pollutants and precursors that react to form secondary air pollutants [4].

According to their nature, the pollutants may be classified in two groups:

Suspensions and aerosols, Gases and toxic vapors.

Suspensions and aerosols are formed of liquid or solid particles with a dimension between 100 and $0.001 \mu \mathrm{m}$.

At a larger dimension the stability in the atmosphere is so low that the disperse system cannot be made, causing the particles with dimensions under $1 \mu \mathrm{m}$ to be part of the molecular dispersion domain. This disperse system is classified according to size and behavior in the atmosphere into three categories: Suspensions bigger than $10 \mu \mathrm{m}$,

Suspensions with a diameter between 10 and 0.1 $\mu \mathrm{m}$,

Suspensions with a size smaller than $0.1 \mu \mathrm{m}$.

The pollutant aerosols may be solid or liquid, according to their state of aggregation, gases and toxic vapors represent the pollutants, which exist in the atmosphere in the shape of gas. With a great diversity in their chemical nature, they have high stability in the atmosphere as well as high diffusion power.

The sources of air pollution can be classified in two groups:

Natural sources,

Artificial sources (results of human activity, anthropogenic).

All the pollutants produced by these sources are called "primary pollutants". The term secondary pollutant is linked to the term secondary effect on the environment.

Natural sources can cause only in exceptional cases important pollution of the environment. The most common natural pollution is the one with powders formed from the erosion of the soil's superficial layers and lifted by the wind at a certain altitude.

Anthropogenic sources are more important and their multiplication is a cause for which air protection represents a vital problem of the contemporary world.

In particular

The artificial sources of air pollution can be classified in:

Stationary pollution sources,

Mobile pollution sources.

The stationary pollution sources comprise the combustion processes and various industrial processes. The combustion processes, like fuel combustion for energy, are used in industrial purposes in order to obtain the necessary caloric energy for heating.

Of all the industrial sources, the thermoelectric plants represent the most important source of air pollution through combustion processes. However, the polluted area is limited to the territory found under the influence of the plant. Home heating, is a very important source of air 
pollution because pollution sources are wide spread in communities.

Various industrial processes represent sources of atmospheric pollution of great importance due to the large diversity of emitted pollutants as well as due to their intense aggression. Practically, any process of obtaining a material or an object can become, in lack of preventive measures, a source of pollution.

The chemical industry pollutes the atmosphere with products resulted from chemical reactions. The effect of pollution is felt on a vast area around these industrial locations.

The mobile sources of pollution are represented by the road, railway, air and marine means of transport. Auto vehicles occupy the first place, from the point of view of pollution.

Transportation based on internal combustion fuels (running fossil fuels) is an especially important source of atmospheric pollution. The pollutant emissions of auto vehicles have two particularities: elimination is done very close to the soil, fact that leads to the achievement of high concentrations on low altitudes. Secondly, the emissions are made on the entire surface of the area and the differences between concentrations depend on the intensity of traffic and the possibilities of street ventilation [5].

Air quality in Europe is slowly improving. However, between 2000 and 2014, a significant proportion of the urban population in the EU-28 was exposed to concentrations of certain air pollutants above the EU limit or target values. Even more people were exposed were even higher in relation to the more stringent World Health Organization (WHO) air quality guideline values set for the protection of human health [6].

Improving air quality is a significant aspect of promoting sustainable human settlements. Data1 may be used to: 1 . To monitor trends in air pollution as a basis for prioritizing policy actions; 2. To map levels of air pollution in order to identify hotspots or areas in need of special attention; 3 . To help assess the number of people exposed to excess levels of air pollution; 4. To monitor levels of compliance with air quality standards, in order to assess the effects of air quality policies; 5. To help investigate associations between air pollution and health effects [7].

Air quality is very often confronted with odours, that even in small amounts, generate discomfort. Unfortunately these odours can very difficult measured and monitored, but still proposals and methods exist to depict, at least major representatives. In the above paper it is indicated that. The Cair CLIP sensors 12 have been developed recently. These gas sensors are based on electro-chemicals or semiconductors. They are used to ensure health and safety, mostly in open spaces or even on closed ones, at work, by measuring occupational exposure values in ppm. In the original time display mode, the level of pollution measured appears on the screen only when a specific threshold is reached. In the air quality measurement mode, the concentration of H2S and mercaptans is given continuously [8].

Proposals of the gadgets. Short description

First proposal for the simple gadget to measure air pollution

In the figure 1 , we can notice the simplicity of this gadget. The device will have the following main components:

Measuring sensors for: PM 2.5, PM 10, NOX; LCD for each sensor;

Microcontroller

LI-Ion battery

The necessary materials are not costly, fact that will bring about a high profit. The small dimensions offer it high portability. The device can be attached on backpacks or bags for example or it can even be worn. Its utility stands in the ability to measure the following pollutants: PM2.5, PM10, and NOX.

The main characteristics of the device are:

Complete autonomous use from other devices; Portability;

Setting of a pre-established critical limit for each pollutant;

Alarming the user when the critical value is overpassed;

Extremely simple use, accessible to all age categories;

Real-time pollutant measurements

This is a device, which mainly addresses children and old people because of its very simple way of use.

Instructions to be achieved:

Turn on the device;

Select the desired pollutant;

Verify that the value measured is displayed on the LCD screen;

For a new measurement of the same pollutant, press reset; 
A led will indicate the moment in which the battery needs recharging

If the maximum admitted value is reached for one of the pollutants, an alarm will go off.

All three pollutants can be measured at the same time.

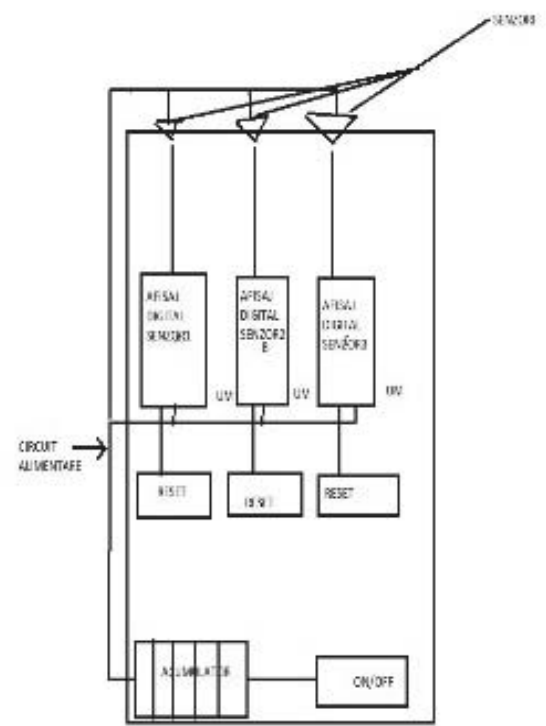

Figure 1. Principle rough draft of the first device.

Second proposal for a more complex gadget to measure air pollution

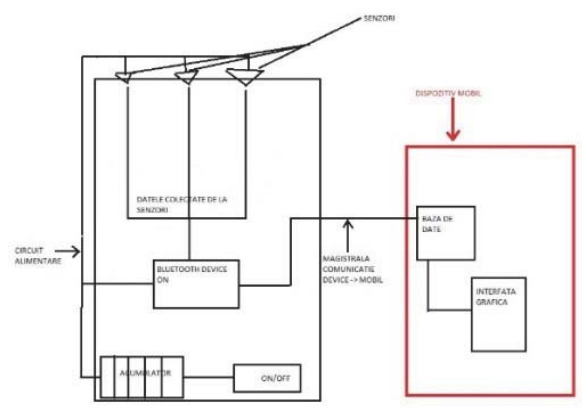

Figure 2. Principle rough draft of the second device.

The second device that we propose, functions together with a mobile device with which it communicates.

It consists of the following main components:

Measuring sensors for PM 2.5, PM10, $\mathrm{NO}_{\mathrm{X}}$, Bluetooth mode,

LI-Ion battery or photovoltaic panel.

Due to the fact that this device communicates with a mobile device, a mobile application must be created in order to install the device on the mobile phone. Python or another programming language will be used to write the code. The application will be written both for mobile devices (telephones, pads) with an Android operating system as well as for IOS.

This device can be easily put absolutely anywhere in the outdoors as long as it communicates with another device for data transmission. For example, it can be put on the hood of a car while being connected to the driver's mobile phone. The driver will receive real-time data for all three pollutants. If the device is put on the hood of a car then photovoltaic panels could be used to charge it.

The data can be stored on the mobile device, shared with other users, or sent directly to institutions authorized in air pollution measurement.

A notification will be sent on the mobile device when the maximum pre-established value for one of the pollutants is reached.

The main characteristics of this device are:

Real time measurement of all three pollutants;

The possibility to choose photovoltaic panels as energy source;

It addresses most people who have a mobile phone or a pad with Bluetooth;

The mobile app will have a graphical interface, making the usage of the device easier;

Possibility to share the measurement data

The functioning mode is described in the following, by instructions:

Turn on the device,

Install the mobile app on the phone or pad and activate your Bluetooth;

Connect the devices using Bluetooth;

Start measuring the pollutants using the app

Measurement data will be displayed on the mobile phone.

Comparison between the two proposed gadgets

Each of the devices mentioned above has certain advantages and disadvantages. I will proceed in listing them:

Advantages of the first device:

Autonomous function;

No lag in data displaying

No radiations

$100 \%$ portability

Disadvantages of the first device:

It cannot use photovoltaic panels as power 
source.

No graphic interface

Measurements cannot be stored or shared;

It has limited functionality.

Advantages of the second device:

It can be powered through solar energy;

Usable in the automotive industry

Graphic interface which makes interaction with the device easier;

Storing and sharing data

It can be used with any other mobile device with

Bluetooth;

Disadvantages of the second device:

The necessity to use it with another mobile device;

It emits radiation

Higher production costs;

Lag in data transmission.

\section{Conclusions}

The article presents a novel method, based on two gadgets proposed in a simple and more complex form, in order to achieve the local air quality, in an easy but still representative way. The devices can be mobile or static in use, on line, and transmit the data for relevant alert. The pollutants selected to be monitored are the most dangerous, thus representative, for urban areas. The next step is to finalise the mounting of the sensors in the proposed outfit, and start testing and interpreting the results, also in correspondence to an accredited laboratory

\section{Acknowledgment}

This paper has been conceived in the frame of my Phd program, at the Politehnica University of Timisoara. I am grateful to my adviser and the Doctoral school for the support.

\section{References}

A. Author, B. Author and C. Author, Journal Volume (Year) Firstpage.

V. Voicu, Combaterea noxelor în industrie, Editura Tehnică, București 2002

I. Ionel, L. Makra, D. Bisorca, K. Bodnár, G. Tusnády, D. G. Calinoiu, R. M. Balogh, N. St. Lontis, Method to depict the best available position, when relocating monitoring stations, Journal of Environmental Protection and Ecology 18, No 1, 2017, pp 1-9.

D. Dulcea, L. A. Varga, I. Ionel, Study concerning the $\mathrm{NO}_{\mathrm{X}}$ generated by the urban traffic, district heating and individual heating systems from downtown Timisoara, Revista de Chimie, Bucharest, 66(7):1042-1045 · July
2015.

R. Laumbach, Q. Meng, H. Kipen- What can individuals do to reduce personal health risks from air pollution?, Journal of Thoracic Disease. All rights reserved. www.jthoracdis.com J Thorac Dis 2015;7(1):96-107, http://dx.doi.org/10.3978/j.issn.2072-

1439.2014.12.21

E. Trânbițașu, Fizico-chimia mediului: Factorii de mediu şi poluanţii lor, Editura Universităţii Petra-Gaze din Ploiești, 2008.

I. Ionel, L. Makra, D.Bisorca, D. G. Calinoiu, and R.-M. Balogh, From theory to practice concerning air quality monitoring Citation: 1796, 040002 (2017); doi: 10.1063/1.4972380, TIM15-16 Physics Conference AIP Conf. Proc. 1796, 040002-1-040002-6; doi: $10.1063 / 1.4972380$ Published by AIP Publishing. 978-0-7354-1462-4/\$30.00, View online:

http://dx.doi.org/10.1063/1.4972380 View Table of Contents:

http://aip.scitation.org/toc/apc/1796/1 Published by the American Institute of Physics

Cercelaru, I. Ionel, R. M. Balogh, odour causing discomfort and their impact on human health, Journal of Environmental Protection and Ecology 17, No 2, 2016, p. 427-43 